\title{
Identifying Patent Conflicts: TRIZ-Led Patent Mapping
}

\author{
Zheng Li, Mark Atherton* and David Harrison \\ School of Engineering and Design, Brunel University, Uxbridge, UK, UB8 3PH \\ zheng.li@brunel.ac.uk mark.atherton@ @brunel.ac.uk david.harrison@ brunel.ac.uk
}

\begin{abstract}
This paper presents a novel method of patent mapping for visualising conflicts between patent claims that incorporates the Theory of Inventive Problem Solving (TRIZ). The method uses TRIZ engineering parameters as the criteria for evaluating dissimilarities between patent claims, producing a visualisation based on Multi-Dimensional Scaling (MDS) that can be compared with legal judgments.
\end{abstract}

The advantages of the method are that it (a) reduces evaluation complexity by transforming claim-toclaim comparisons into claim-to-criteria comparisons, and (b) provides a means of comparing judgement standards between different legal authorities in mechanical engineering terms. Reliability and validity of the method are tested through focus groups using a case study on aircraft seats. The scope of the method is limited to the field of mechanical inventions.

Keywords: Patent Map, TRIZ, Mechanical Engineering, Patent Claim, Legal Judgment

* Corresponding author: Tel: +44 (0)1895 266690

Email: mark.atherton@brunel.ac.uk

Postal address: School of Engineering and Design, Brunel University, Uxbridge, UB8 3PH, UK. 


\section{Introduction: approaches to patent mapping}

Patent mapping is a series of data mining and visualisation methods based on statistical analysis to reveal relations of information in patents, such as applicants, protection areas, and keywords of technologies, among hundreds and thousands of patents [1]. A literature review of data mining used in patent mapping has been summarised in Table 1. Many text mining models have been developed but only a few approaches can compare and analyse drawings and texts together, such as MultiDimensional Scaling (MDS) [2, 3]. A further adaptation of MDS is presented in this paper.

\section{Table 1}

Objects and models of data mining in patent mapping.

Objects and models of data mining in patent mapping

Objects (data) Massive data from patents such as inventive names, application dates, classification numbers, drawings, and keywords frequently appear in claims and descriptions.

SOFM model (Yoon et al., 2002) [4]; NLP-based (Cascini et al., 2004) [5], CVS model (Uchida et al. 2004) [6]; K-means \& semantic network theory (Kim et al., 2007; Suh and Park, 2006) [7,

Existing models 8]; SoTRM model (Suh and Park, 2008) [9]; business planning (Lee et al., 2009) [10]; summary sheets (Gelinas, 2010) [11]; GTM model (Son et al., 2011) [12]; decision making framework (Martin and Daim, 2012) [13]; SAO model (Park et al., 2012) [14]; MDS-based (Janssens et al., 2006; Chen, 2009) [15, 2]; Go-chessboard model (Chen and Chen, 2007) [3].

MDS has been widely applied in psychological analysis to evaluate overall impressions or subjective opinions on an object and then derive spatial positions in multidimensional space reflecting these perceptions [16, 17]. In general, defining $n$ as a number of points and $k$ as a number of dimensions/attributes (mathematically, $k$ is a dimension; in MDS evaluations, $k$ is also called an attribute), the major function of MDS is to transform data (e.g., scores arranged from evaluation sheets) from a high dimensional space $(k>>3)$ to a low dimensional space (usually $k \leq 3$ ) through iterative computations that find an optimised low-order matrix that visualises with sufficient clarity the complex correlations in the original matrix (Figure 1). A classic approach to finding and optimising a low-order matrix is a three-step process: constructing a transition matrix and a function; 
solving characteristic roots before constructing characteristic vectors; and comparing row vectors. (A more detailed mathematical description of MDS this mature process can be found in [17].)

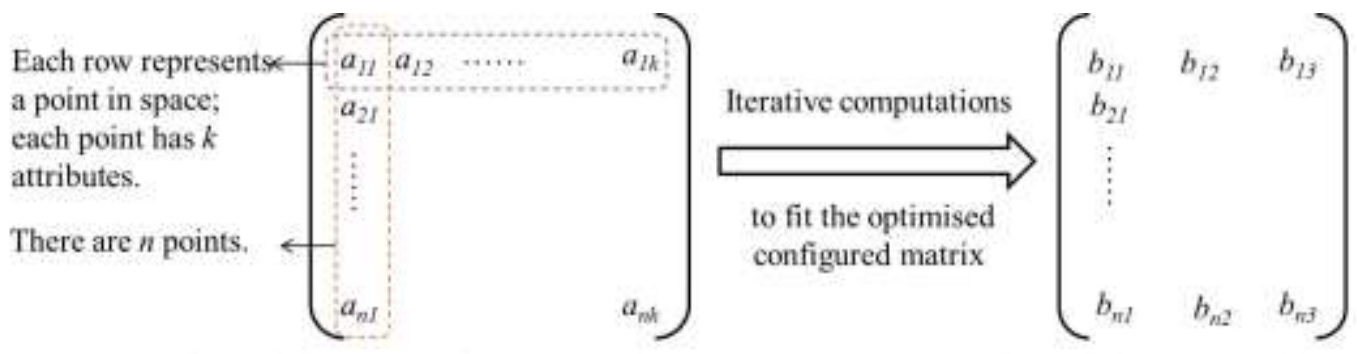

High dimensional space: a $k \times n$ vector matrix, $k>>3 \quad$ Low dimensional space, e,g. $k=3$

Fig. 1. Illustration of reduction of dimensions: the core of data processing in MDS. $n$-number of points; $k$-number of dimensions (attributes).

The input data used in existing MDS-based patent mapping is in the form of experts' opinions, i.e., perceptual evaluations, which is why the term perceptual mapping has also been used in MDS for describing the type of original data that is subjective [16]. This original data has high dimensionality and is termed, perceptual data, $P_{d}$; and is transformed into $2 \mathrm{D}$ or $3 \mathrm{D}$ space of visual data, $V_{d}$, by a mapping rule, $f_{d}: P_{d} \rightarrow V_{d}$, a premised topological relation that maintains the technical correlations. (Figure 2).

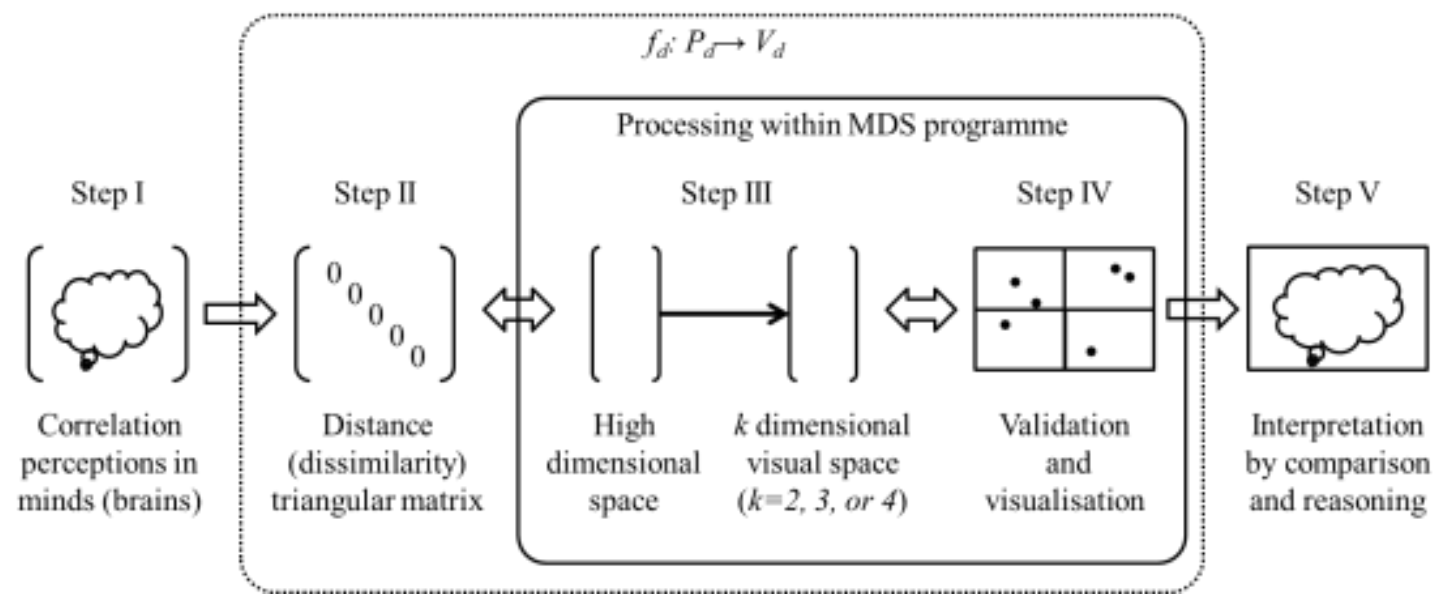

Fig. 2. From perceptual data (high dimensionality) to visual data (2D or 3D): MDS-based patent mapping. $f_{d}$-mapping rules; $P_{d}$-perceptual data; $V_{d}$ —visual data; Topological constants— technical correlations.

A limitation of existing MDS-based patent mapping [2,3] is that it only deals with attribute-free data, which can result in obscure interpretations [16]. For example, if we give a score from 10 to 0 (from 
very similar to not at all similar) to express perceptions of similarity between two patented designs [2], then this score is attribute-free because no specific criteria are identified. Attribute-based evaluations, e.g., Weight and Speed, provide clearer interpretations than attribute-free.

\section{TRIZ-Led Patent Mapping}

We propose an approach combining MDS-based patent mapping with the Theory of Inventive Problem Solving, TRIZ (Russian acronym) in order to identify conflicts between patents. TRIZ is a systematic method for solving mechanical design problems, and also analysing and forecasting technologies $[18,19]$. A comparison of patent mapping and TRIZ is presented in Table 2.

Table 2

Two methods comparison: Patent Mapping and TRIZ.

\begin{tabular}{|c|c|c|}
\hline & Patent mapping & TRIZ \\
\hline History & $\begin{array}{l}\text { Japan Patent Office created the first patent map in } \\
1968 \text { [1]. }\end{array}$ & $\begin{array}{l}\text { In 1956, TRIZ was published by G. Altshuller in } \\
\text { Russia [18]. }\end{array}$ \\
\hline Purpose & To present correlations of information in patents. & To solve technical problems for inventing. \\
\hline $\begin{array}{l}\text { General } \\
\text { description }\end{array}$ & $\begin{array}{l}\text { Visualised competitive intelligence (like maps), } \\
\text { based on statistical analysis methods such as text } \\
\text { mining, reveals correlations and trends of } \\
\text { technologies, which are references for managers } \\
\text { and lawyers to make decisions. }\end{array}$ & $\begin{array}{l}\text { A toolbox for innovation, deriving from the studies } \\
\text { on thousands of patented technologies, serves } \\
\text { engineers and designers with guidelines and } \\
\text { inspiring principles to solve inventive problems, } \\
\text { avoiding trial-and-error thinking. }\end{array}$ \\
\hline Logic & $\begin{array}{l}\text { From induction (theory establishing) to deduction } \\
\text { (application process). }\end{array}$ & $\begin{array}{l}\text { From induction (theory establishing) to deduction } \\
\text { (application process). }\end{array}$ \\
\hline $\begin{array}{c}\text { Main } \\
\text { outcomes } \\
\text { (contributions) }\end{array}$ & $\begin{array}{l}\text { Inventor ranking; Technology theme correlation; } \\
\text { Opportunity forecasting/risk early-warning; } \\
\text { Competitive strategies }\end{array}$ & $\begin{array}{l}\text { Technology evolution trend; Ideal final result } \\
\text { Contradictory analysis (matrix); Substance-field } \\
\text { analysis }\end{array}$ \\
\hline
\end{tabular}

The TRIZ general engineering parameters are a set of high-level technical descriptors for defining designs, derived from the study of patent literature [20, 21]. The combined method, TRIZ-Led Patent Mapping, reveals potential risks of conflicts between claims (indirectly between technical features) in competing patents. In a patent each (low-level) technical feature defines its contribution to the invention; whereas a claim is a legal description defining the matter for which protection is sought in terms of at least one of these technical features [22]. If a technical feature in one patent conflicts with 
the technical feature in another patent then this conflict will also exist at a higher technical level. Therefore, comparing high-level TRIZ engineering parameters instead of low-level technical features will be a more efficient means of effective comparison of patents. As claims are based on low-level technical features then they can be transformed into high-level TRIZ engineering parameters in order to identify patent conflicts.

The word conflict represents two conditions: infringement, which means existing claims read on ('read on' is a legal phrase, meaning 'describe or present') an accused device (one that is under suspicion of infringement); and invalid, which means claims in a suspicious patent read on prior arts ('prior art' is a legal phrase meaning previous patents) [23].

Previous research connecting TRIZ and patent classification [24, 25] has been used to classify patents for inventive purposes and technical trends analysis but did not consider technical features between patents for finding infringement or invalidity. There are only a few papers on potential patent infringement identification, such as Cascini et al [26], which are excellent works based on elegant text mining methods. However, in most patent law systems there is a reliance on evaluation by patent examiners and generalist engineers, which means that subjective judgment is inevitable [27]. Hence, while automatic text mining can reduce subjectivity, a method that accommodates human evaluations will be more suitable for identifying potential patent infringement.

\subsection{Framework of the method}

We use the 39 TRIZ parameters as criteria for evaluation to form a new method for collecting attribute-based data. In practice, too many of these parameters will result in difficulties for data collection and calculations; whereas most problems only need to employ a subset of the 39 parameters. There are three parts to the TRIZ-led patent-mapping method: I evaluation; II calculation and visualisation; and III interpretation. Part II is fulfilled by computation; Part I and Part III are determined by the expert user. 


\subsubsection{Evaluation}

We introduce an evaluation sheet called a TRIZ relevance matrix (Figure 3), in order to identify the technical features in patented technologies that can be linked to the TRIZ parameters. Three types of items are entered in this matrix with reference to patent claims in conjunction with patent diagrams:

(i) Left column: technical features, represented by claims in practice;

(ii) Top row: TRIZ parameters to be used as elements of criteria; and

(iii) A marker is placed wherever a claim has relevance to a criterion.

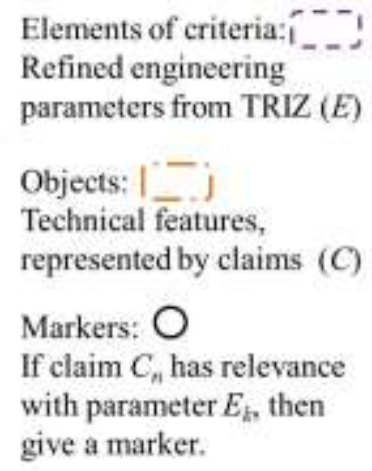

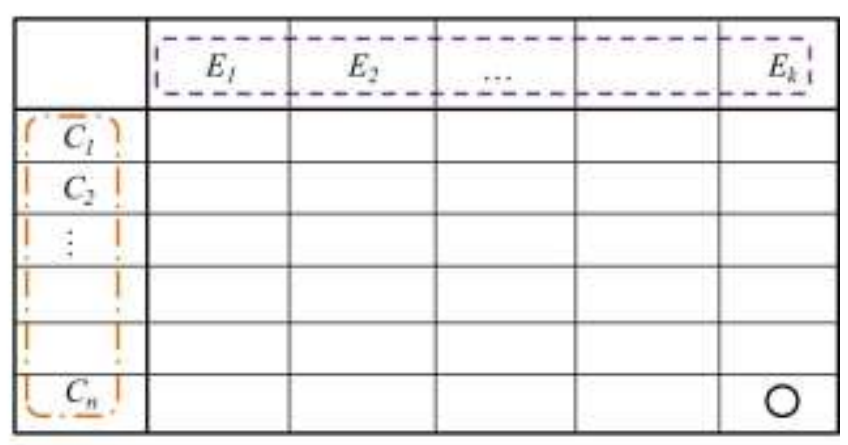

Fig. 3. Explanation of an evaluation sheet.

In Figure 3, the columns represent criteria, similar to the columns in the Figure 1, which are attributes. Criteria and attributes have the same meaning here but used in different contexts: attributes are used in MDS; criteria are used in the evaluation sheet. As there are many kinds of inventions, e.g., mechanical inventions, chemical inventions, etc., there are different kinds of criteria. The TRIZ parameters are one specific kind of criteria/attributes used only for mechanical inventions.

The 39 TRIZ parameters are refined to a smaller set, firstly 17, then 12 parameters (Figure A.1 and Figure A.2), in order to improve the evaluation efficiency by using the following rules:

(a) Remove TRIZ parameters judged to be irrelevant to the technical features of the problem;

(b) If the TRIZ parameter descriptions are similar then they are combined and given a new title. 
Machine tool patents were assembled by a focus group in order to assess the consistency of results with regards to three sets of evaluation criteria $(39,17$, and 12 parameters, see Table A.1) using Cronbach's method [28]. The Cronbach's Alpha value of 0.875 (Figure A.3) is better than the normally acceptable value of 0.7 and just under the value of 0.9 normally considered to be very good [29]. Therefore, the refined set of 12 parameters is adopted as the initial set of evaluation criteria for TRIZ-Led Patent Mapping (see the validity test in Section 3.2).

\subsubsection{Calculation and visualisation}

If two claims, $C i$ and $C j$ ( $i$ and $j$ represent order numbers of features) share $m_{i j}$ common TRIZ parameters, and the total number of TRIZ parameters related to the two claims is $k_{i}+k_{j}$, then the similarity, $s_{i j}$, can be calculated by equation (1).

$$
s_{i j}=\frac{2 m_{i j}}{k_{i}+k_{j}}
$$

The result is 1 if two claims have exactly the same correlations with TRIZ parameters; and the result is 0 if there are no TRIZ parameters common to both.

The TRIZ relevance matrix is then transformed into a dissimilarity matrix using equation (2), where, $d$, represents dissimilarity.

$$
d=1-s
$$

Figure 4 shows how the TRIZ relevance matrix is used to calculate the similarity, which is eventually recorded in a triangular matrix of dissimilarity calculation results. 
Similarity calculation

An example of the evaluation sheet

\begin{tabular}{|c|c|c|c|c|c|c|c|}
\hline \multicolumn{2}{|c|}{} & \multicolumn{6}{|c|}{$\begin{array}{c}\text { Elemets of criteria: refined } \\
\text { IRIZ parameters }\end{array}$} \\
\cline { 2 - 8 } \multicolumn{2}{c|}{} & $E_{1}$ & $E_{2}$ & $E_{3}$ & $E_{1}$ & $E_{5}$ & $k$ \\
\hline \multirow{2}{*}{$\begin{array}{c}\text { Technical } \\
\text { features, } \\
\text { represented } \\
\text { by claims }\end{array}$} & $C_{1}$ & 0 & 0 & 0 & & 0 & 4 \\
\cline { 2 - 8 } & $C_{3}$ & 0 & & & 0 & 0 & 3 \\
\cline { 2 - 8 } & $C_{1}$ & & 0 & 0 & 0 & & 3 \\
\cline { 2 - 8 } & $C_{3}$ & & & & 0 & & 1 \\
\hline
\end{tabular}

\begin{tabular}{|c|c|c|}
\hline Claim & Similarity & Interpretation \\
\hline$C_{1}-C_{2}$ & 0.57 & \multirow{10}{*}{$\begin{array}{l}\text { Taking } C_{1} \text { for instance, } \\
C_{3} \text { has the most } \\
\text { similarities with } C_{1} \\
\text { among all the five } \\
\text { features while } C_{4} \text { is } \\
\text { totally different from } \\
C_{1} C_{2} \text { and } C_{3} \text { have the } \\
\text { same similarity as } C_{1} \\
\text { but these two are not } \\
\text { very similar to each } \\
\text { other }(0.33) \text {. }\end{array}$} \\
\hline$C_{1}-C_{3}$ & 0.57 & \\
\hline$C_{1}-C_{4}$ & 0 & \\
\hline$C_{1}-C_{5}$ & 0.86 & \\
\hline$C_{2}-C_{3}$ & 0.33 & \\
\hline$C_{2}-C_{4}$ & 0.5 & \\
\hline$C_{2}-C_{5}$ & 0.33 & \\
\hline$C_{3}-C_{4}$ & 0.5 & \\
\hline$C_{3}+C_{5}$ & 0.67 & \\
\hline$C_{1}-C_{5}$ & 0 & \\
\hline
\end{tabular}

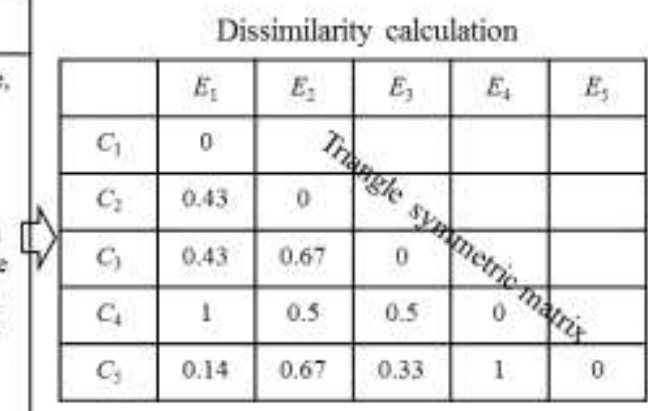

Fig. 4. Process of relevance evaluation, similarity calculation, and dissimilarity calculation.

The ratio values in the dissimilarity matrix represent the evaluators' perceptions of relations between technical features. The matrix data is put into SPSS (a statistics software, SPSS 18.02, 2013) in order to produce the patent maps. We choose $3 \mathrm{D}$ mapping, not $2 \mathrm{D}$, because $3 \mathrm{D}$ is a better way than $2 \mathrm{D}$ to configure correlations of the original input data.

\subsubsection{Interpretation}

When interpreting the patent map in Figure 5, the axes are only used for establishing a space of dissimilarity between technical features or claims by MDS.

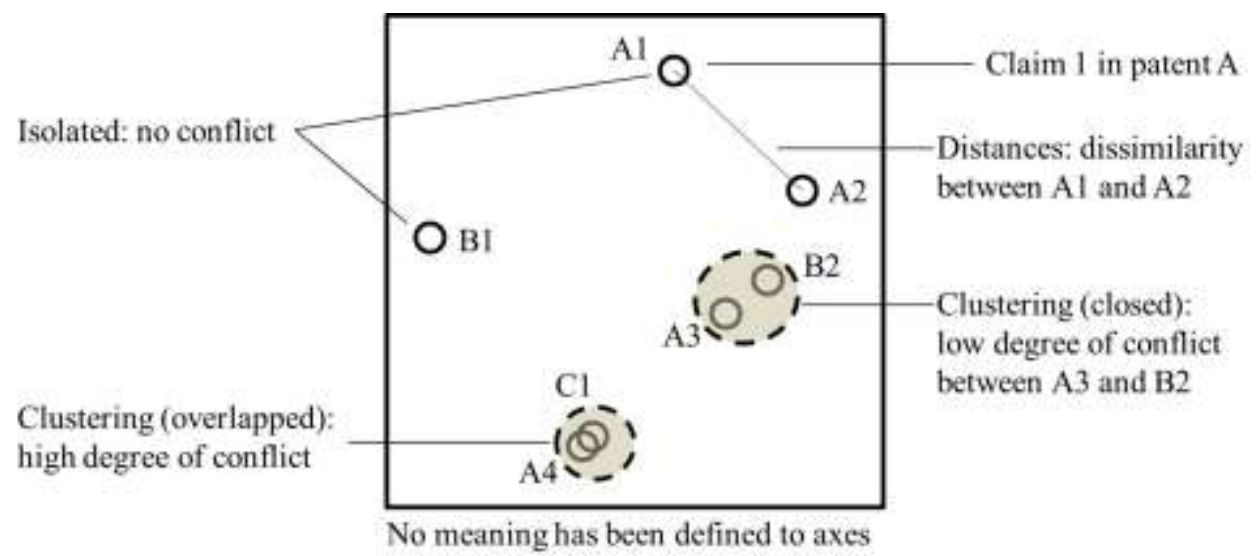

Fig. 5. Sample of a mapping result of TRIZ-Led Patent Mapping. 
Random initialisation of the MDS process means that the initial point positioning in the patent map is arbitrary, as it is the closeness of points that matters in judging whether technical features are similar or not. Distances between points are akin to correlations between the technical features but the space between points and the axes have no physical or useful meaning.

\subsection{Algorithm and programming of the method}

Figure 6 shows a summary of the process in the form of a simplified algorithm. The algorithm has been programmed in MATLAB and developed to integrate the time-consuming evaluation procedure into an efficient process, as well as saving the time of matrix calculations.

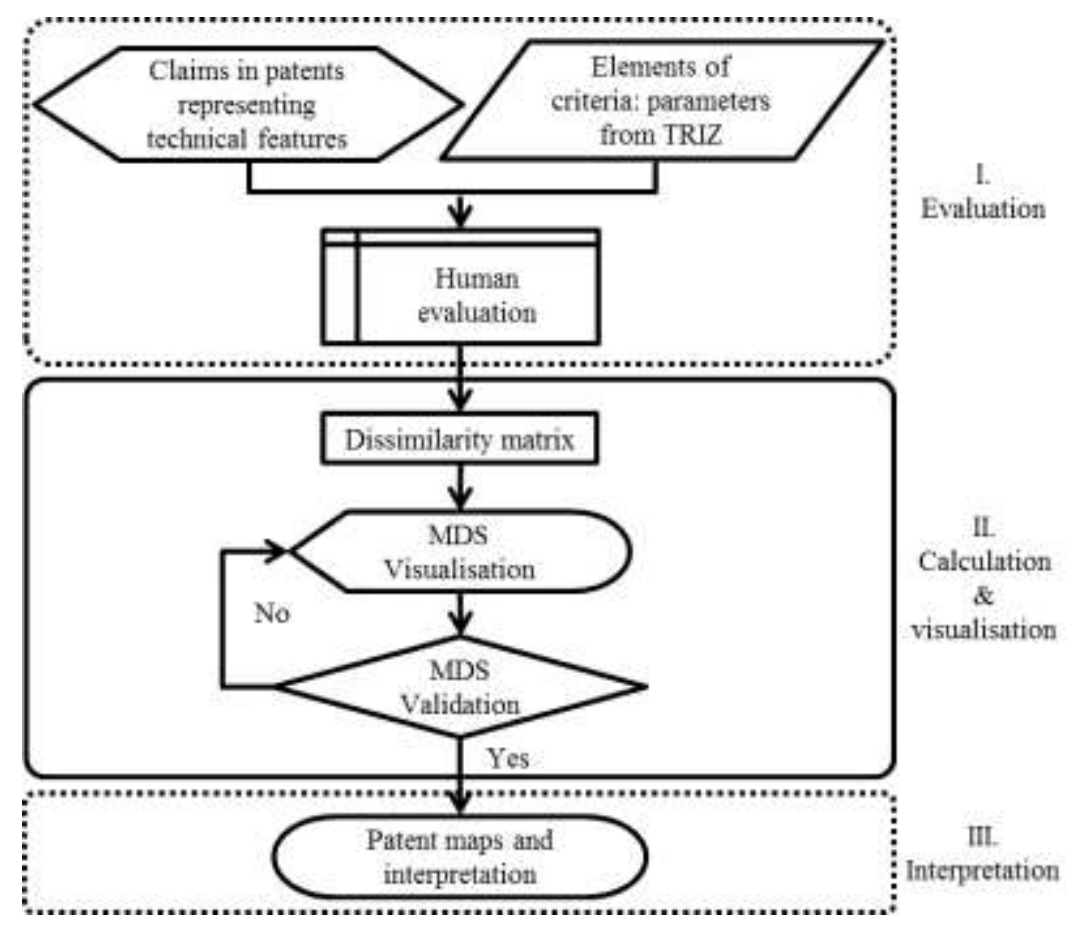

Fig. 6. Algorithm of TRIZ-Led Patent Mapping.

The interface of the programme used in the case study is shown in Figure 7. It was nearly 72 times faster than hand calculations when the number of evaluation objects (claims) was around 30. An information sheet of how to use the interface was provided to the evaluators. 

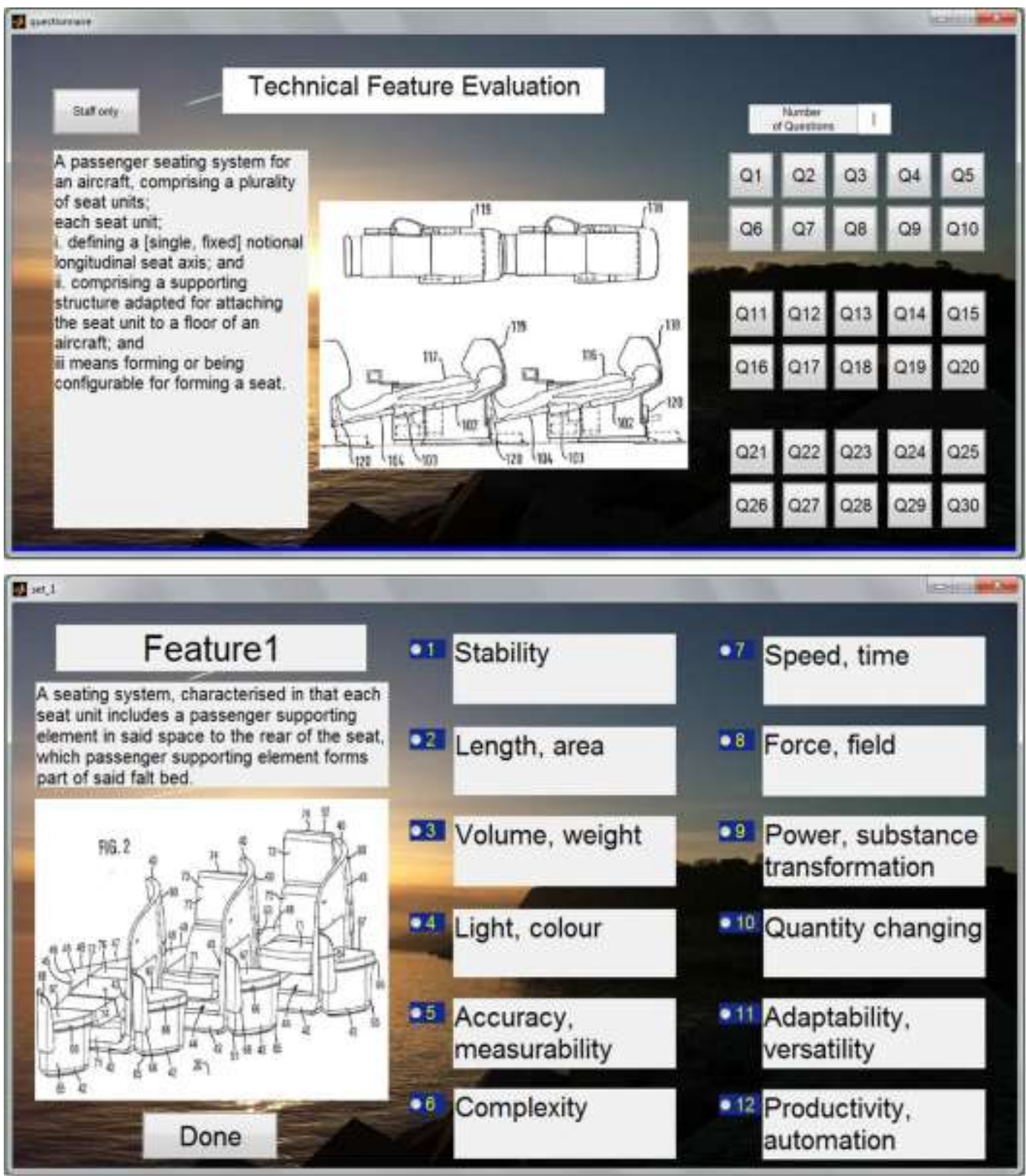

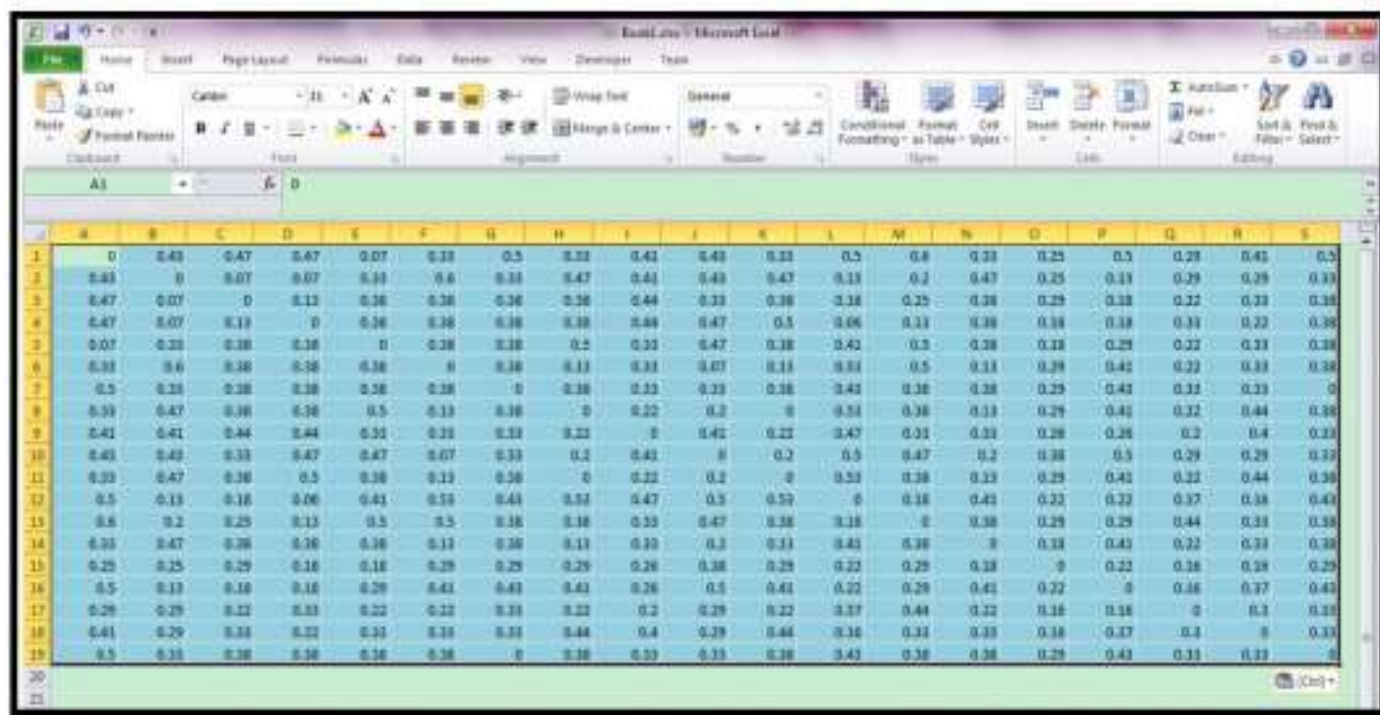

Fig. 7. The user interface for TRIZ-Led Patent Mapping (sample): the processes from top to bottom are evaluating claims; selecting attributes/criteria; and generating matrix. 


\section{Validation: reliability and validity}

Validation of the method is based on a mechanical aircraft seat case study. Two tests are used in the following order: (i) a test of reliability that verifies the consistency of the similarity calculations between different evaluators; and (ii) a combined test of sensitivity and specificity that assesses the validity of different sets of evaluation criteria (criteria set).

\subsection{Reliability test: consistency between evaluators}

Reliability generally refers to consistent results in repeated tests [30]. Consistency was tested via focus groups using the evaluation sheet (Table A.2). There were only slight differences of evaluation results between evaluators because of intra-group discussions. No significant difference was found between the evaluation results of the two groups.

\subsection{Validity test: sensitivity and specificity between criteria sets}

The meaning of validity usually depends upon a researcher's understanding of the specific problem [30]. We assess the validity of our method by comparing mapping results with actual legal judgments. In the aircraft seat case, there are two legal judgments: the search report for patent application from the European Patent Office (EPO) [31] and the court judgments of patent invalidity lawsuits from the UK courts $[32,33]$. Table 3 shows the results.

Table 3

Conflict and non-conflict claims identified between mapping results and legal judgments.

\begin{tabular}{c|ccc}
\hline & Mapping results using $\boldsymbol{E}_{\mathbf{1 2}}{ }^{*}$ & Legal judgments \\
& EPO search report & UK court judgments \\
\hline Conflict claims & A $1 ; 6 ; 8-9 ; 11$ & A $1 ; 3-11$ & A $1 ; 9$ \\
Non-conflict claims & A2-5; $7 ; 10$ & A2 & A2-8, 10-11 \\
\hline
\end{tabular}

* The sets of criteria have different numbers of (refined) TRIZ parameters and are symbolised as $E_{k}$, e.g., $E_{12}$, means the criteria set adopting 12 elements (i.e., 12 refined TRIZ parameters).

A combined test of sensitivity and specificity [34] is implemented to test performances of the criteria set $E_{12}$ (Table 4). Sensitivity measures the proportion of legal judgments of conflict claims that are 
correctly identified by our method (i.e. Sensitivity $=$ common conflict claims/total conflict claims in the legal judgement); while specificity measures the proportion of legal judgments of non-conflict claims that are correctly identified by our method (i.e. Specificity $=$ common no-conflict claims/total no-conflict claims in the legal judgement) [35].

Table 4

Combined test of sensitivity and specificity between mapping results and legal judgments.

\begin{tabular}{|c|c|c|c|c|c|}
\hline & & \multicolumn{2}{|c|}{ Mapping results using $E_{12}$} & & \multirow{2}{*}{$\begin{array}{l}\text { Sensitivity and } \\
\text { specificity }\end{array}$} \\
\hline & & $\begin{array}{l}\text { Conflict } \\
\text { A1;6;8-9; } 11\end{array}$ & $\begin{array}{l}\text { No conflict } \\
\text { A2-5; } 7 ; 10\end{array}$ & Total & \\
\hline \multirow{2}{*}{$\begin{array}{l}\text { EPO search } \\
\text { report }\end{array}$} & $\begin{array}{l}\text { Conflict } \\
\text { A1; 3-11 }\end{array}$ & $\begin{array}{l}\text { i.e. } 5 \text { common claims } \\
\text { (A1;6;8-9,11) }\end{array}$ & $\begin{array}{l}\text { i.e. } 5 \text { mis-identified } \\
\text { claims }(\mathrm{A} 3-5 ; 7 ; 10)\end{array}$ & 10 & Sensitivity $=5 / 10=50 \%$ \\
\hline & $\begin{array}{l}\text { No conflict } \\
\text { A2 }\end{array}$ & 0 common claims & 1 common claim & 1 & Specificity $=1 / 1=100 \%$ \\
\hline \multirow{2}{*}{$\begin{array}{l}\text { UK court } \\
\text { judgments }\end{array}$} & $\begin{array}{l}\text { Conflict } \\
\text { A } 1 ; 9\end{array}$ & $\begin{array}{l}2 \text { common claims } \\
(\mathrm{A} 1 ; 9)\end{array}$ & $\begin{array}{l}0 \text { mis-identified } \\
\text { claims }\end{array}$ & 2 & Sensitivity $=2 / 2=100 \%$ \\
\hline & $\begin{array}{l}\text { No conflict } \\
\text { A2-8, 10-11 }\end{array}$ & $\begin{array}{l}3 \text { common claims } \\
(\mathrm{A} 6 ; 8,11)\end{array}$ & $\begin{array}{l}6 \text { common claims } \\
(\mathrm{A} 2-5 ; 7,10)\end{array}$ & 9 & Specificity $=6 / 9=67 \%$ \\
\hline
\end{tabular}

Based on the initial criteria set $E_{12}$, two new criteria sets $E_{15}$ and $E_{12 \mathrm{~b}}$ (i.e. a new set of $E_{12}$ ) are developed (see Table A.3 and Section 5.4) and the tests in Table 4 repeated in Table 5.

Table 5

Tests of sensitivity and specificity of different criteria sets between legal judgments.

\begin{tabular}{c|cc|cc}
\hline \multirow{2}{*}{ Evaluation criteria sets } & \multicolumn{2}{|c|}{ Compared with EPO search report } & \multicolumn{2}{c}{ Compared with UK court judgments } \\
& Sensitivity & Specificity & Sensitivity & Specificity \\
\hline$E_{12}$ & $50 \%$ & $100 \%$ & $100 \%$ & $67 \%$ \\
$E_{15}$ & $100 \%$ & $25 \%$ & $100 \%$ & $44 \%$ \\
$E_{12 \mathrm{~b}}$ & $100 \%$ & $17 \%$ & $50 \%$ & $56 \%$ \\
\hline
\end{tabular}

Table 5 shows that it is difficult to simultaneously achieve a high sensitivity and a high specificity and also that sometimes they will be biased towards one or the other for different legal judgements. If we want to correctly identify conflict claims, then the criteria set with the higher sensitivity $\left(E_{15}\right)$ is selected; conversely, if we want to correctly identify the non-conflict claims, then the set with higher specificity $\left(E_{12}\right)$ is selected. 


\section{Application demonstration: the aircraft seat case}

The mechanical aircraft seat case is the same as used in Section 3. We present the evaluation result in

Table B.1, and display the mapping results in Figure 8. For demonstration, we compare the mapping result only with the court judgments [32,33]. The patents involved are EP1495908A1, GB2326824A, and EP1211176B1 [31, 36, 37], which were respectively marked as A, B, and C.
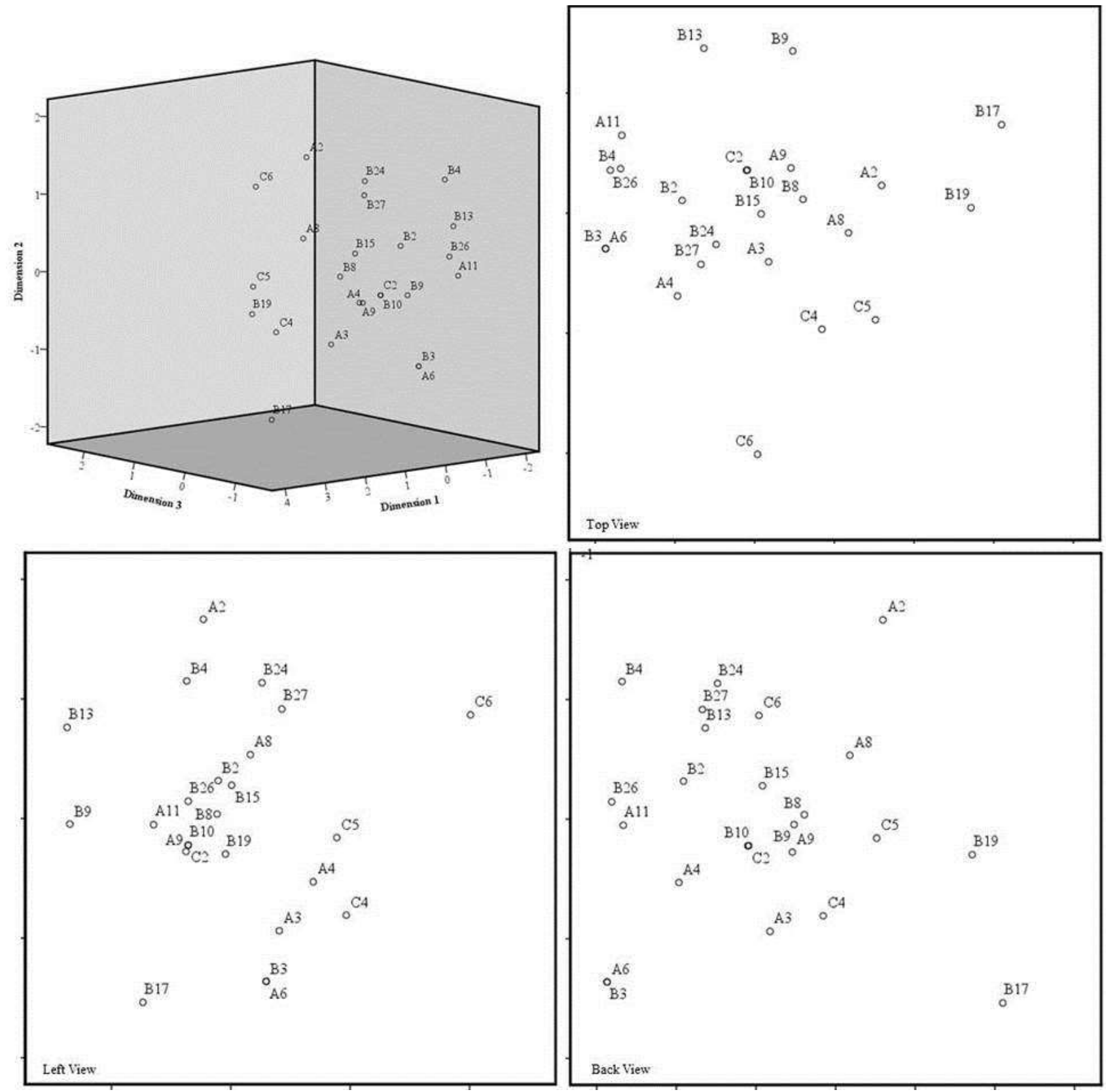

Fig. 8. TRIZ-Led Patent Mapping (using $E_{12}$ ) of the aircraft seat case. (Stress $=0.15$ and $R S Q=0.91$, from SPSS)

Remark: A1 is an independent claim so we ignore its evaluation but it is indirectly included in the comparison by virtue of the claims that depend on it, i.e. A6, which is identified as a conflict claim. 
Interpretation of the TRIZ-Led Patent Mapping results of Figure 8 follows four steps:

Step 1: Identify conflict claims in mapping results. The clustering claims were marked by circles in Figure 9, indicating that the conflicts exist between these claims A6, B3; A11, B26; and A9, B8, B10, B15, C2. As a result, all the suspect conflict claims in the target patent are: A1, A6, A9, and A11.

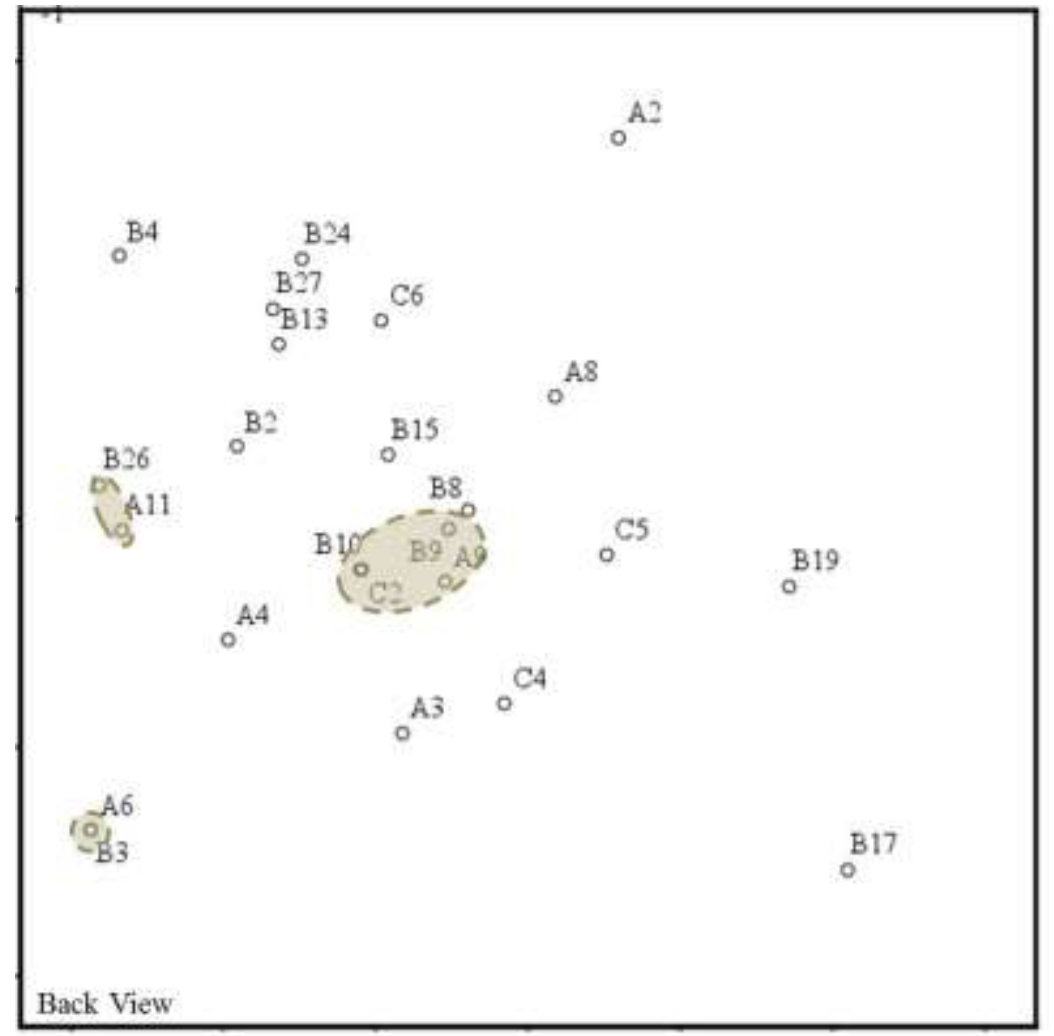

Fig. 9. Clustering of the claims by observing the closeness in 3D maps (using $E_{12}$ ).

Step 2: Compare mapping results with those in legal judgments. Checking the court judgments in the lawsuits, patent A was accused of revocation because of partial invalidity - its claims may partially interfere with the claims in B and C. In the judgment, A1 and A9 were particularly emphasised as the controversial claims. A1 was an independent claim comprising all its other claims. Our mapping results reveal the specific conflict claims depended on A1: A6, A8 and A11; meanwhile, A9 was emphasised particularly. 
Step 3: Assess the sensitivity and specificity of the criteria set used $\left(E_{12}\right)$. The value of sensitivity is $100 \%$ and the specificity is $67 \%$ (Table 4$)$.

Repeat the steps above to compare the mapping results for the EPO search report.

Step 4: Integrate the values of sensitivity and specificity into a Receiver Operating Characteristic (ROC) plot [34]. The relationship between the legal judgments, as processed by our method, is represented as the two points shown in Figure 10, which has in effect used the mapping results as a benchmark in order to compare the legal judgments from the two authorities. A high specificity and a low sensitivity are associated with strict judgment standards [34]. However, here the EPO examiners are seen to have used different standards for judging claim conflict compared with that of the UK courts.

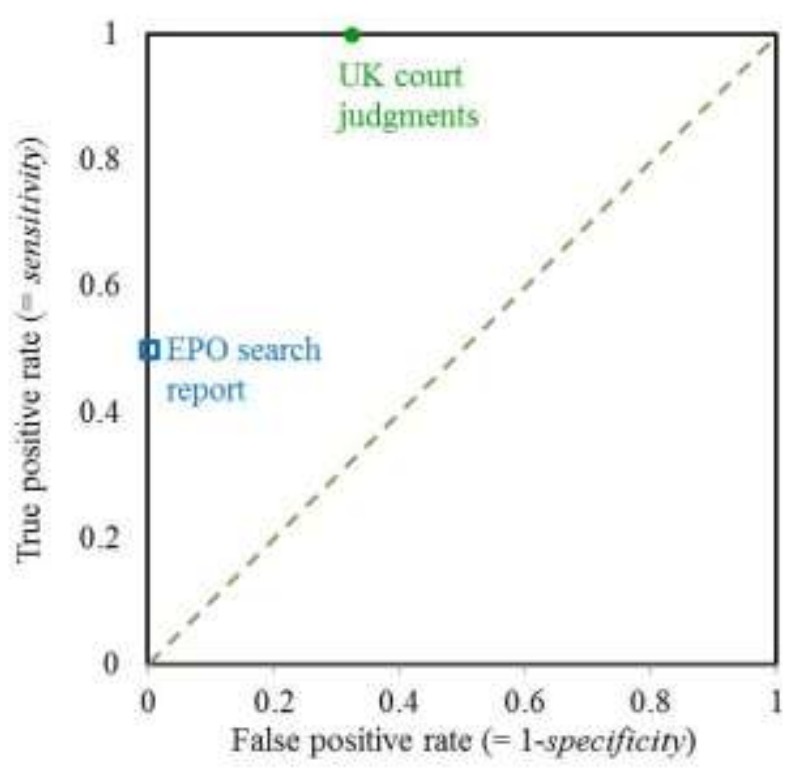

Fig. 10. Comparing different judgment standards between legal authorities (using the mapping results using $E_{12}$ )

In addition, two important points are: (i) the patent granted dates have not been used in our method because the comparison between technical features in claims is the main concern; (ii) the descriptions and drawings in the patents are necessary for explanations of claims. This is considered in our user interface (Figure 7). 


\section{Discussion}

\subsection{Relation of attribute-free and attribute-based in MDS}

Attribute-based data is adopted in the method, whereas previous researchers have used attribute-free data. According to the literature [38, 39], there is scope for using attribute-based and/or attribute-free data as valid types of data input for MDS even though some prefer using attribute-free evaluation methods. However, using attribute-free data for patent maps will mean the user has to guess what the attributes are that form the basis of the plots viewed, resulting in ambiguous interpretation. The TRIZ parameters provide a sound technological basis for including attributes in the analysis.

\subsection{Using claims to represent technical features}

Directly using patent claims in our method instead of technical features is a means of achieving a high efficiency because extracting low-level technical features from claims takes much more time than just adopting the claims that are then transformed into high-level TRIZ parameters. The number of claims is not related to the number of technical features [32]. In the UK and European patent systems, it is commonly understood by patent judges and patent attorneys that they cannot rely on claims alone in conflict judgment because proving that there is a conflict between claims is not a proof of conflict between technical features [32]. Therefore, introducing TRIZ as a mediation linking claims to technical features, and achieving this link with more efficiency, are benefits of our method.

\subsection{Alternative statistical methods}

Statistical methods for patent text mining are mostly based on Natural Language Processing (NLP) [40], which could be considered for use in our method instead of human evaluation. However, NLP is limited to identification and classification, not understanding meaning or even inferring technical correlations in patents. This determines that human evaluation is still necessary in our method. 
An alternative statistical approach to clustering other than MDS is Hierarchical Clustering Analysis (HCA) [16], which rather than generating a patent map based on direct pair-wise comparisons, the tree structure of HCA does not show isolated claims as clearly as MDS at the lower clustering levels.

There are statistical methods that could refine the 39 TRIZ parameters into a smaller set a posteriori, e.g., Principal Component Analysis (PCA) and Singular Value Decomposition (SVD) [41]. However, these methods can only reduce numbers of parameters by extraction whereas we intend to reduce some numbers of parameters by combination also (Section 2.1.1). Consequently, neither PCA, SVD or other statistical method were used for deciding a priori subsets of evaluation criteria.

\subsection{Choosing evaluation criteria}

As the initial criteria set $\left(E_{12}\right)$ had resulted in some missing and incorrectly identified claims in the mapping results (Table 4$)$, we developed the new criteria sets $\left(E_{15}\right.$ and $\left.E_{12 \mathrm{~b}}\right)$ by increasing either sensitivity or specificity of the initial set. In order to increase sensitivity, we deleted and combined existing parameters. In order to increase specificity, we added new parameters, e.g. Balance, identified from design principles [42]; and separated existing parameters (e.g., Moving became Rotating and Translating).

\subsection{Practical limitations}

Admittedly, achieving high efficiency of the method has to be balanced with the accuracy of results. Table 4 shows that our method misidentified some conflict claims in comparison with those of legal judgments. Three possible reasons are: (i) excluding basic information in patents, e.g., priority date and descriptions, which can lead to claim conflicts; (ii) using patent claims instead of technical features, which is an insufficient way to identify conflicts; and (iii) the evaluation criteria are not statistically valid and reliable, which results in bias. 


\section{Conclusions}

Introducing TRIZ parameters as mediation to identify patent conflicts is a novel contribution to the field of patent management.

TRIZ-Led Patent Mapping, although with some limitations, is one of the few ways to efficiently identify conflicts between patent claims in mechanical engineering. And it enables the comparison of legal judgments in mechanical engineering terms, which is potentially useful in patent strategy and policy that supports decision-making for inventors, R\&D managers, patent attorneys, patent examiners, and perhaps even patent court judges.

There are two suggestions for further research: (i) to use other visualisation methods for interpretation of the results; and (ii) more case studies can be carried out for sensitivity and specificity tests to select preferable criteria sets and reveal further relationships between legal judgments.

\section{References}

[1] Japan Patent Office (JPO). Guide book for practical use of patent map for each technology field. Invention Research Institute, Japan Institute of Invention and Innovation, 2000.

[2] Chen, R. Design patent map visualization display. Expert Systems with Applications 2009; 36: 12362-74.

[3] Chen, A., Chen, R. Design patent map: an innovative measure for corporative design strategies. Engineering Management Journal 2007; 19, 3: 14-29.

[4] Yoon, B. U., Yoon, C. B., Park, Y. T. On the development and application of a self-organizing feature map-based patent map. R\&D Management 2002; 32, 4: 291-300. 
[5] Cascini, G., Fantechi, A., Spinicci, E. Natural Language Processing of Patent and Technical Documentation. Document Analysis System (6th International Workshop, DAS 2004, Florence, Italy), Lecture Notes in Computer Science (LNCS) 3163, 2004: 508-20.

[6] Uchida, H., Mano, A., Yukawa, T. Patent map generation using concept-based vector space model. Working Notes of NTCIR-4 2004.

[7] Kim, Y. G., Suh, J. H., Park, S. C. Visualization of patent analysis for emerging technology. Expert Systems with Applications 2007; 34: 1804-12.

[8] Suh, J. H., Park, S. C. A new visualisation method for patent map: application to Ubiquitous computing technology. ADMA 2006, LNAI 2006; 4093: 566-73.

[9] Suh, J. H., Park, S. C. Service-oriented technology roadmap (SoTRM) using patent map for R\&D strategy of service industry. Expert systems with applications 2008; 36: 6754-72.

[10] Lee, S., Yoon, B., Lee, C., Park, J. Business planning based on technological capabilities: patent analysis for technology-driven roadmapping. Technological Forecasting \& Social Change 2009; 76: 796-9.

[11] Gelinas, P. Mapping early patents on Baker's yeast manufacture. Comprehensive reviews in Food Science and Food Safety 2010; 9: 483-97.

[12] Son, C., Suh, Y., Jeon, J., Park, Y. Development of a GTM-based patent map for identifying patent vacuums. Expert Systems with Applications 2011; 39: 2489-500.

[13] Martin, H., Daim, T. U. Technology roadmap development process (TRDP) for the service sector: a conceptual framework. Technology in Society 2012; 34: 94-105.

[14] Park, H., Yoon, J., Kim, K. Identifying patent infringement using SAO based semantic technological similarities. Scientometrics 2012; 90: 515-29.

[15] Janssens, F.; Leta, J.; Glänzel, W.; De Moor, B. Towards mapping library and information science. Information Processing and Management 2006; 42: 1614-42.

[16] Hair, J. F., Andeson, R. E., Tatham, R. L., Black, W. C. Multivariate data analysis with readings, fourth ed. Prentice-Hall International, New Jersey, 1995.

[17] Ren, X, S., Yu, X, L. Multi-dimensional statistical analysis, second ed. China Statistics Press, Beijing, 2011. 
[18] Altshuller, G. The Innovation Algorithm: TRIZ, Systematic innovation, and technical creativity. Technical Innovation Centre, Worcester, MA, 1999.

[19] Mann, D. An introduction to TRIZ: The Theory of Inventive Problem Solving. Creative and Innovation Management-TRIZ 2001; 10: 123-5.

[20] Bogatyreva O.A., Pahl A, K., Vincent J. F.V. Enriching TRIZ with biology: The biological effects database and implications for teleology and epistemology. ETRIA World Conference, Strasbourg, 6-8 November, 2002.

[21] Mann, D.L., Dewulf, S., Updating TRIZ - 1985-2002 Patent Research findings. TRIZCON'03, Philadelphia, 2003.

[22] Guidelines for Examination in European Patent Office and Glossary. [Online] Available at: http://www.epo.org/lawpractice/legal-texts/html/guidelines/e/f_v_2.htm, http://www.epo.org/service-support/glossary.html\#t, and http://www.epo.org/law-practice/legal-texts/html/guidelines/e/f_iv_3_8.htm, [Accessed 10/2012].

[23] Goldstein, A. N. Patent law for scientists and engineers. Taylor \& Francis Group, Florida, 2005.

[24] Liang, Y., Tan, R., Wang, C., Li, Z. Computer-aided Classification of Patents Oriented to TRIZ. Proceedings of the 2009 IEEE IEEM.

[25] Li, Z., Tate, D., Lane, C., Adams, C. A framework for automatic TRIZ level of invention estimation of patents using natural language processing, knowledge-transfer and patent citation metrics. Computer-Aided Design 44, 2014 : $987-$ 1010.

[26] Cascini, G., Zini, M. Measuring patent similarity by comparing inventions functional trees. International Federation for Information Processing (IFIP) Vol 277, Computer-Aided Innovation (CAI) 2008: 31-42.

[27] Li, J. The Innovation and Inspiration of the Non-Obviousness Standard of Invention Patent in the U.S. Dissertation of the East China University of Political Science and Law, 2008.

[28] Cronbach, L. J. Coefficient alpha and the internal structure of tests. Psychometrika, 1951; 16: $297-334$.

[29] Kline, P. The handbook of psychological testing ( $2^{\text {nd }}$ edition). London: Routledge, 2000:13.

[30] Golafshani, N. Understanding Reliability and Validity in Qualitative Research. The Qualitative Report, 8, 2003: 597-607.

[31] Ferry, D., Wells, A. B. A seating systems and a passenger accommodation unit for a vehicle, European Patent EP 1495908A1. 2002.

[32] Virgin v Zodiac [2009] EWCA Civ 1062. 
[33] Virgin v Zodiac, [2013] UKSC 46, 2013.

[34] Fawcett, T. An introduction to ROC analysis. Pattern Recognition Letters, 27, 2006: 861-874.

[35] Altman, D. G., Bland, J. M. Diagnostic test 1: sensitivity and specificity. British Medical Journal, 308, 1994:1552.

[36] Dryburgh, I., Lunn, S., Mulchansingh, R. A seating unit for an aircraft, Great Britain Patent GB 2326824A. 1999.

[37] Hansmann, D. Passenger seat arrangement in an aircraft cabin, European Patent EP 1211176 B1. 2001.

[38] Blake, B. F., Schulze, S., Hughes, J. M. Perceptual Mapping by Multidimensional Scaling: A Step by Step Primer. Research Report in Consumer Behaviour, 2003.

[39] Sun, J., Zhao, H., Zhao, Y., Hu. F. Empirical study of corporate social responsibility overlap based on multidimensional scaling analysis. Mathematics in Practice and Theory 2011; 41, 9: 106-14.

[40] Abbas, A., Zhang, L., Khan, S.U. A literature review on the state-of-the-art in patent analysis. World Patent Information, 2014:1-11.

[41] Verhaegen, P.-A., D’hondt, J., Vandevenne, D., Dewulf, S., Duflou, J. R. Identifying candidates for design-byanalogy. Computers in Industry, 62, 2011: 446-459.

[42] Zelanshi, P., Fisher, M.P. Design principles and problems, $2^{\text {nd }}$ Edition, Harcourt Brace College Publishers. 1996. 


\section{Biography}

Zheng Li has his MEng degree in Mechanical Engineering in China and MA degree in Design Strategy and Innovation in the UK. He is a $\mathrm{PhD}$ student at Brunel University, interested in design research including patent strategy and design evaluation. Zheng.Li@brunel.ac.uk

Mark Atherton (corresponding author) has a BSc (Hons) in Mechanical Engineering (Aston), an MSc in Industrial Robotics and Manufacturing Automation, and PhD in Mechanical Engineering Design. He is a Reader in Engineering Design at Brunel University with particular interests in robustness and design optimisation. Mark.Atherton@brunel.ac.uk

David Harrison has a BSc in Engineering Science and a $\mathrm{PhD}$ in Robotics. He is a Chartered Engineer and Member of the Institute of Engineering and Technology. He holds a Chair in Design in the School of Engineering and Design at Brunel University, and his research interests include design research, printed electronics, and sustainable design. David.Harrison@brunel.ac.uk 


\section{Appendix A}

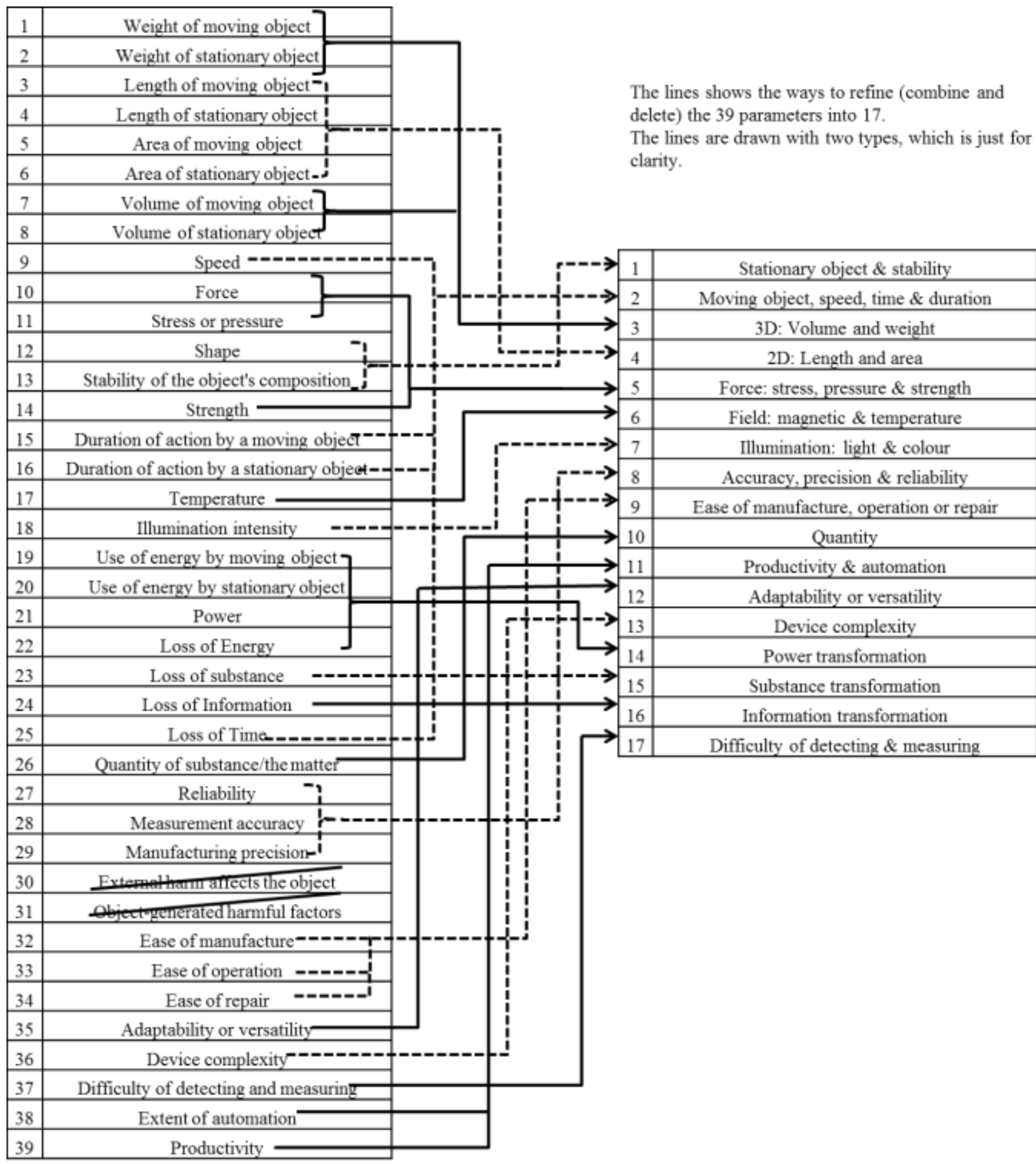

Fig. A.1. Refining engineering parameters in TRIZ: from 39 to 17. 


\section{Appendix A}

\begin{tabular}{|c|c|}
\hline 1 & Weight of moving object \\
\hline 2 & Weight of stationary object \\
\hline 3 & Length of moving object \\
\hline 4 & Length of stationary object \\
\hline 5 & Area of moving object \\
\hline 6 & Area of stationary object \\
\hline 7 & Volume of moving object \\
\hline 8 & Volume of stationary object \\
\hline 9 & Speed \\
\hline 10 & Force \\
\hline 11 & Stress or pressure \\
\hline 12 & Shape \\
\hline 13 & Stability of the object's composition \\
\hline 14 & Strength \\
\hline 15 & Duration of action by a moving object \\
\hline 16 & Duration of action by a stationary object \\
\hline 17 & Temperature \\
\hline 18 & Illumination intensity \\
\hline 19 & Use of energy by moving object \\
\hline 20 & Use of energy by stationary object \\
\hline 21 & Power \\
\hline 22 & Loss of Energy \\
\hline 23 & Loss of substance \\
\hline 24 & Loss of Information \\
\hline 25 & Loss of Time \\
\hline 26 & Quantity of substance/the matter \\
\hline 27 & Reliability \\
\hline 28 & Measurement accuracy \\
\hline 29 & Manufacturing precision \\
\hline 30 & External harm affects the object \\
\hline 31 & Object-generated harmful factors \\
\hline 32 & Ease of manufacture \\
\hline 33 & Ease of operation \\
\hline 34 & Ease of repair \\
\hline 35 & Adaptability or versatility \\
\hline 36 & Device complexity \\
\hline 37 & Difficulty of detecting and measuring \\
\hline 38 & Extent of automation \\
\hline 39 & Productivity \\
\hline
\end{tabular}

\begin{tabular}{|c|c|c|}
\hline \multicolumn{2}{|c|}{ New labels } & Refined from \\
\hline 1 & Stability, reliability \& security & $2,4,6,8,13,27$ \\
\hline 2 & Length, angle, area \& layout & $3,4,5,6,12$ \\
\hline 3 & Volume, weight, intensity \& capacity & $7,8,18$ \\
\hline 4 & Light, colour \& temperature & 17,18 \\
\hline 5 & Accuracy \& measurability & $28,29,37$ \\
\hline 6 & Complexity \& diversity & 36 \\
\hline 7 & Movement, speed \& time & $15,16,25$ \\
\hline 8 & Force \& field & $9,10,11,14$ \\
\hline 9 & Power, substance transformation & $19,20,21,22,23$ \\
\hline 10 & Quantity \& quantity changing & 26 \\
\hline 11 & Adaptability \& versatility & 35 \\
\hline 12 & Productivity, manufacturing, automation \& repair & Omitted: $24,30,31,33,34$ \\
\hline & &
\end{tabular}

Fig. A.2. Refining engineering parameters in TRIZ: from 39 to 12 
Appendix A

\begin{tabular}{|c|c|c|}
\hline \multicolumn{3}{c|}{ Reliability Statistics } \\
\begin{tabular}{|c|c|} 
Cronbach's \\
Alpha
\end{tabular} & $\begin{array}{c}\text { Cronbach's } \\
\text { Alpha Based on } \\
\text { Standardized } \\
\text { Items }\end{array}$ & N of Items \\
\hline 0.875 & 0.906 & 28 \\
\hline
\end{tabular}

Fig. A.3. Results from SPSS of consistency between three sets of criteria: 39, 17 and 12 parameters.

\section{Table A.1.}

Consistency of evaluation results between using different sets of evaluation criteria.

\begin{tabular}{|c|c|c|c|c|c|c|c|c|c|c|c|c|c|c|c|c|c|c|c|c|c|c|c|c|c|c|c|c|}
\hline & $D_{23} *$ & $D_{24}$ & $D_{25}$ & $D_{26}$ & $D_{27}$ & $D_{28}$ & $D_{29}$ & $D_{34}$ & $D_{35}$ & $D_{36}$ & $D_{37}$ & $D_{38}$ & $D_{39}$ & $D_{45}$ & $D_{46}$ & $D_{47}$ & $D_{48}$ & $D_{49}$ & $D_{56}$ & $D_{57}$ & $D_{58}$ & $D_{59}$ & $D_{67}$ & $D_{68}$ & $D_{69}$ & $D_{78}$ & $D_{79}$ & $D_{89}$ \\
\hline$E_{39}$ & 0.23 & 0.60 & 0.40 & 0.40 & 0.50 & 0.50 & 0.64 & 0.56 & 0.56 & 0.56 & 0.64 & 0.64 & 0.60 & 0.67 & 0.00 & 0.75 & 0.75 & 0.43 & 0.00 & 0.25 & 0.25 & 0.43 & 0.25 & 0.25 & 0.43 & 0.00 & 0.56 & 0.56 \\
\hline$E_{1}$ & 0.00 & 0.17 & 0.23 & 0.23 & 0.23 & 0.23 & 0.45 & 0.17 & 0.23 & 0.23 & 0.23 & 0.23 & 0.45 & 0.45 & 0.45 & 0.45 & 0.45 & 0.33 & 0.00 & 0.00 & 0.00 & 0.60 & 0.00 & 0.00 & 0.60 & 0.00 & 0.60 & 0.60 \\
\hline$E_{17}$ & 0.25 & 0.54 & 0.13 & 0.11 & 0.25 & 0.22 & 0.22 & 0.38 & 0.13 & 0.22 & 0.25 & 0.60 & 0.11 & 0.54 & 0.60 & 0.54 & 0.60 & 0.47 & 0.11 & 0.13 & 0.22 & 0.11 & 0.22 & 0.10 & 0.20 & 0.11 & 0.11 & 0.20 \\
\hline
\end{tabular}

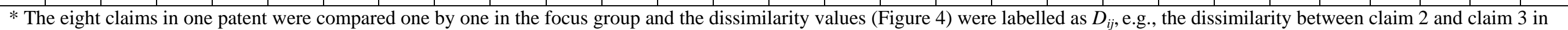
the patent was $D_{23}$. 


\section{Appendix A}

Table A.2.

Example of the evaluation sheet in focus group studies*.

\begin{tabular}{|c|c|c|c|c|c|c|c|c|c|c|c|c|}
\hline & 1 & 2 & 3 & 4 & 5 & 6 & 7 & 8 & 9 & $\mathbf{1 0}$ & 11 & 12 \\
\hline & $\begin{array}{c}\text { Stability, } \\
\text { reliability \& } \\
\text { security }\end{array}$ & $\begin{array}{c}\text { Length, } \\
\text { angle, area \& } \\
\text { layout }\end{array}$ & $\begin{array}{l}\text { Volume, weight, } \\
\text { intensity \& } \\
\text { capacity }\end{array}$ & $\begin{array}{l}\text { Light, colour \& } \\
\text { temperature }\end{array}$ & $\begin{array}{c}\text { Accuracy \& } \\
\text { measurability }\end{array}$ & $\begin{array}{l}\text { Complexity \& } \\
\text { diversity }\end{array}$ & $\begin{array}{l}\text { Movement, } \\
\text { speed \& time }\end{array}$ & $\begin{array}{l}\text { Force } \\
\& \text { filed }\end{array}$ & $\begin{array}{l}\text { Power, substance } \\
\text { transformation }\end{array}$ & $\begin{array}{c}\text { Quantity \& } \\
\text { quantity } \\
\text { changing }\end{array}$ & $\begin{array}{c}\text { Adaptability \& } \\
\text { versatility }\end{array}$ & $\begin{array}{c}\text { Productivity, } \\
\text { manufacturing, } \\
\text { automation \&repair }\end{array}$ \\
\hline A1 & $\mathrm{O}$ & $\mathrm{O}$ & & & & & & $\mathrm{O}$ & & & $\mathrm{O}$ & \\
\hline C3 & & & & & $\mathrm{O}$ & $\mathrm{O}$ & $\mathrm{O}$ & & $\mathrm{O}$ & $\mathrm{O}$ & $\mathrm{O}$ & \\
\hline
\end{tabular}

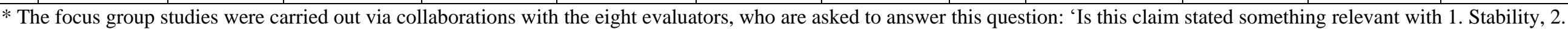

Length, 3. ...?' If yes, then make a mark there; if no, then leave the place blank.

Table A.3.

Development of evaluation criteria sets.

\begin{tabular}{|c|c|c|c|c|c|c|c|c|c|c|c|c|c|c|c|}
\hline & 1 & 2 & 3 & 4 & 5 & 6 & 7 & 8 & 9 & 10 & 11 & 12 & 13 & 14 & 15 \\
\hline$E_{15}$ & Force & Field & Rotating & Translating & Material* & Accurate/complex & Replaced & $\begin{array}{c}3 \mathrm{D} \\
\text { structure }\end{array}$ & Stable & Subsystem & $\begin{array}{c}2 \mathrm{D} \\
\text { arrangement } \\
\end{array}$ & Cycle/repeated & Direction/angle & Interface & $\begin{array}{l}\text { Transformation of } \\
\text { energy/substance }\end{array}$ \\
\hline$E_{12 b}$ & & Field & Rotating & Translating & Material & Accurate & Replaced & $\begin{array}{l}\text { Special } \\
\text { layout }\end{array}$ & Balance & $\begin{array}{c}\text { Sub- } \\
\text { system/structure }\end{array}$ & Array & Cycle & Angle & & \\
\hline
\end{tabular}

* According to our experience in the tests, some elements of the evaluation criteria are modified or added based on the TRIZ parameters such as Material, Cycle, etc. 


\section{Appendix B}

Table B.1

TRIZ parameter relevance evaluation sheet (using 12 parameters).

\begin{tabular}{|c|c|c|c|c|c|c|c|c|c|c|c|c|c|c|c|c|c|c|c|c|c|c|c|c|}
\hline & A2 & A3 & A4-5 & $66-7$ & A8 & A9-10 & A11 & B2 & B3 & $\begin{array}{r}\mathrm{B} 4-7,11,21- \\
23,25\end{array}$ & B8 & B9 & B10-12 & B13 & B15-16 & B17-18 & B19-20 & B24 & B26 & B27-33 & $\mathrm{C} 2-3$ & $\mathrm{C} 4$ & C5 & C6-7 \\
\hline A2 & 0.00 & 0.50 & 0.71 & 1.00 & 0.20 & 0.40 & 0.71 & 0.50 & 1.00 & 0.67 & 0.27 & 0.50 & 0.56 & 0.43 & 0.40 & 0.67 & 0.43 & 0.43 & 0.75 & 0.40 & 0.56 & 0.71 & 0.33 & 0.50 \\
\hline A3 & 0.50 & 0.00 & 0.14 & 0.33 & 0.40 & 0.20 & 0.43 & 0.25 & 0.33 & 0.67 & 0.27 & 0.50 & 0.33 & 0.43 & 0.40 & 0.67 & 0.43 & 0.43 & 0.50 & 0.40 & 0.33 & 0.43 & 0.33 & 0.50 \\
\hline A4-5 & 0.71 & 0.14 & 0.00 & 0.20 & 0.56 & 0.33 & 0.33 & 0.14 & 0.20 & 0.60 & 0.40 & 0.43 & 0.25 & 0.33 & 0.33 & 1.00 & 0.67 & 0.33 & 0.43 & 0.33 & .25 & 0.33 & .50 & .43 \\
\hline A6-7 & 1.00 & 0.33 & 0.20 & 0.00 & 0.75 & 0.50 & 0.20 & 0.33 & 0.00 & 0.50 & 0.56 & 0.67 & 0.43 & 0.60 & 0.50 & 1.00 & 1.00 & 0.60 & 0.33 & 0.50 & 0.43 & 0.60 & 0.71 & 0.67 \\
\hline A8 & 0.20 & 0.40 & 0.56 & 0.75 & 0.00 & 0.17 & 0.56 & 0.40 & 0.75 & 0.50 & 0.08 & 0.40 & 0.27 & 0.56 & 0.17 & 0.50 & 0.33 & 0.33 & 0.60 & 0.33 & 0.27 & 0.33 & 0.09 & 0.40 \\
\hline A9-10 & 0.40 & 0.20 & 0.33 & 0.50 & 0.17 & 0.00 & 0.33 & 0.20 & 0.50 & 0.50 & 0.08 & 0.20 & 0.09 & 0.33 & 0.17 & 0.50 & 0.33 & 0.33 & 0.40 & 0.33 & 0.09 & 0.33 & 0.27 & 0.60 \\
\hline A11 & 0.71 & 0.43 & 0.33 & 0.20 & 0.56 & 0.33 & 0.00 & 0.14 & 0.20 & 0.20 & 0.40 & 0.43 & 0.25 & 0.33 & 0.33 & 1.00 & 1.00 & 0.33 & 0.14 & 0.33 & 0.25 & 0.67 & 0.75 & 0.71 \\
\hline B2 & 0.50 & 0.25 & 0.14 & 0.33 & 0.40 & 0.20 & 0.14 & 0.00 & 0.33 & 0.33 & 0.27 & 0.25 & 0.11 & 0.14 & 0.20 & 1.00 & 0.71 & 0.14 & 0.25 & 0.20 & 0.11 & 0.43 & 0.56 & 0.50 \\
\hline B3 & 1.00 & 0.33 & 0.20 & 0.00 & 0.75 & 0.50 & 0.20 & 0.33 & 0.00 & 0.50 & 0.56 & 0.67 & 0.43 & 0. & 50 & 1.00 & 1.00 & 0.60 & 0.33 & 0.50 & .43 & 0.60 & 0.71 & 0.67 \\
\hline $\begin{array}{c}\text { B4-7.,14,21- } \\
23,25\end{array}$ & 0.67 & 0.67 & 0.60 & 0.50 & 0.50 & 0.50 & 0.20 & 0.33 & 0.50 & 0.00 & 0.56 & 67 & 0.43 & 0.60 & 0.50 & 1.00 & 1.00 & 0.20 & 0.33 & 0.50 & 0.43 & 0.60 & 0.71 & 0.67 \\
\hline B8 & 0.27 & 0.27 & 0.40 & 0.56 & 0.08 & 0.08 & 0.40 & 0.27 & 0.56 & 0.56 & 0.00 & 0.27 & 0.17 & 0.40 & 0.08 & 0.56 & 40 & 0.40 & 0.45 & .23 & .17 & 0.40 & 0.17 & 0.45 \\
\hline B9 & 0.50 & 0.50 & 0.43 & 0.67 & 0.40 & 0.20 & 0.43 & 0.25 & 0.67 & 0.67 & 0.27 & 0.00 & 0.11 & 0.14 & 0.20 & 0.67 & 0.43 & 0.43 & 0.50 & 0.40 & 0.11 & 0.43 & 0.56 & 0.75 \\
\hline B10-12 & 0.56 & 0.33 & 0.25 & 0.43 & 0.27 & 0.09 & 0.25 & 0.11 & 0.43 & 0.43 & 0.17 & 0.11 & 0.00 & 0.25 & 0.09 & 0.71 & 0.50 & 0.25 & 0.33 & 0.27 & 0.00 & 0.25 & 0.40 & 0.56 \\
\hline B13 & 0.43 & 0.43 & 0.33 & 0.60 & 0.56 & 0.33 & 0.33 & 0.14 & 0.60 & 0.60 & 0.40 & 0.14 & 0.25 & 0.00 & 0.33 & 1.00 & 0.67 & 0.33 & 0.43 & 0.33 & 0.25 & 0.67 & 0.75 & 0.71 \\
\hline B15-16 & 0.40 & 0.40 & 0.33 & 0.50 & 0.17 & 0.17 & 0.33 & 0.20 & 0.50 & 0.50 & 0.08 & 0.20 & 0.09 & 0.33 & 0.00 & 0.75 & 0.56 & 0.33 & 0.40 & 0.17 & 0.09 & 0.33 & 0.27 & 0.40 \\
\hline B17-18 & 0.67 & 0.67 & 1.00 & 1.00 & 0.50 & 0.50 & 1.00 & 1.00 & 1.00 & 1.00 & 0.56 & 0.67 & 0.71 & 1.00 & 0.75 & 0.00 & 0.20 & 1.00 & 1.00 & 1.00 & 0.71 & 0.60 & 0.43 & 1.00 \\
\hline B19-20 & 0.43 & 0.43 & 0.67 & 1.00 & 0.33 & 0.33 & 1.00 & 0.71 & 1.00 & 1.00 & 0.40 & 0.43 & 0.50 & 0.67 & 0.56 & 0.20 & 0.00 & 0.67 & 1.00 & 0.78 & 0.50 & 0.33 & 0.25 & 0.71 \\
\hline B24 & 0.43 & 0.43 & 0.33 & 0.60 & 0.33 & 0.33 & 0.33 & 0.14 & 0.60 & 0.20 & 0.40 & 0.43 & 0.25 & 0.33 & 0.33 & 1.00 & 0.67 & 0.00 & 0.43 & 0.33 & 0.25 & 0.33 & 0.50 & 0.43 \\
\hline B26 & 0.75 & 0.50 & 0.43 & 0.33 & 0.60 & 0.40 & 0.14 & 0.25 & 0.33 & 0.33 & 0.45 & 0.50 & 0.33 & 0.43 & 0.40 & 1.00 & 1.00 & 0.43 & 0.00 & 0.20 & 0.33 & 0.71 & 0.78 & 0.50 \\
\hline В27-33 & 0.40 & 0.40 & 0.33 & 0.50 & 0.33 & 0.33 & 0.33 & 0.20 & 0.50 & 0.50 & 0.23 & 0.40 & 0.27 & 0.33 & 0.17 & 1.00 & 0.78 & 0.33 & 0.20 & 0.00 & 0.27 & 0.56 & 0.45 & 0.20 \\
\hline $\mathrm{C} 2-3$ & 0.56 & 0.33 & 0.25 & 0.43 & 0.27 & 0.09 & 0.25 & 0.11 & 0.43 & 0.43 & 0.17 & 0.11 & 0.00 & 0.25 & 0.09 & 0.71 & 0.50 & 0.25 & 0.33 & 0.27 & 0.00 & 0.25 & 0.40 & 0.56 \\
\hline $\mathrm{C} 4$ & 0.71 & 0.43 & 0.33 & 0.60 & 0.33 & 0.33 & 0.67 & 0.43 & 0.60 & 0.60 & 0.40 & 0.43 & 0.25 & 0.67 & 0.33 & 0.60 & 0.33 & 0.33 & 0.71 & 0.56 & 0.25 & 0.00 & 0.25 & 0.43 \\
\hline C5 & 0.33 & 0.33 & 0.50 & 0.71 & 0.09 & 0.27 & 0.75 & 0.56 & 0.71 & 0.71 & 0.17 & 0.56 & 0.40 & 0.75 & 0.27 & 0.43 & 0.25 & 0.50 & 0.78 & 0.45 & 0.40 & 0.25 & 0.00 & 0.33 \\
\hline C6-7 & 0.50 & 0.50 & 0.43 & 0.67 & 0.40 & 0.60 & 0.71 & 0.50 & 0.67 & 0.67 & 0.45 & 0.75 & 0.56 & 0.71 & 0.40 & 1.00 & 0.71 & 0.43 & 0.50 & 0.20 & 0.56 & 0.43 & 0.33 & 0.00 \\
\hline
\end{tabular}

